\title{
Karpal Tünel Sendromunda Kortikosteroid Fonoforezi ve Lokal Kortikosteroid Enjeksiyonu Tedavilerinin Klinik Etkinliğinin Karșılaștırılması
}

\section{Comparison of Clinical Effectiveness of Corticosteroid Phonophoresis and Local Steroid Injection Treatment in Carpal Tunnel Syndrome}

\author{
Süeda RÜKŞEN, Bengi ÖZ, Neşe ÖLMEZ, Asuman MEMIŞ \\ Atatürk Eğitim ve Araştırma Hastanesi, Fiziksel Tıp ve Rehabilitasyon Anabilim Dalı, Izmir, Türkiye
}

\section{Özet}

Amaç: Karpal tünel sendromlu (KTS) hastalarda uygulanan kortikosteroid enjeksiyonu ile kortikosteroid fonoforez tedavilerinin klinik sonuçlarının karşılaştırılması amaçlandı.

Gereç ve Yöntem: Ellerinde parestezi ve ağrı şikayetleri olan, fizik muayene ve elektromyografi ile KTS tanısı doğrulanan 32 hastanın 40 eli çalışmaya alındı. Hastalar iki gruba ayrıldı. Birinci gruba (20 el) betametazon enjeksiyonu, el-bilek ateli, egzersiz, ikinci gruba (20 el) betametazon fonoforezi, el-bilek ateli, egzersiz uygulandı. Tedavi öncesi ve tedavi sonrası 3. ayda; vizüel analog skala (VAS) ile ağrı şiddeti, Liken skalası ile uyuşma şiddeti, Boston Semptom Şiddet Skalası ve Fonksiyonel Kapasite Skalası ile semptom şiddeti ve fonksiyonel kapasite, Jamar el dinamometresi ile el kavrama gücü, pinçmetre ile lateral ve parmak ucu kavrama gücü, Grooved Pegboard el beceri testi ile parmak ince becerisi değerlendirildi.

Bulgular: Ağrı, uyuşma şiddeti, el kavrama ve parmak gücü, semptom şiddeti ve fonksiyonel kapasite ve parmak beceri testlerinde her iki tedavi grubunda anlamlı düzelme tespit edildi $(p<0,05)$. Gruplar tüm parametrelerdeki iyileşme açısından karşılaştırıldığında gruplar arasında anlamIı fark saptanmadı $(p>0,05)$.

Sonuç: Üç aylık izlem sonunda KTS'li hastaların tedavisinde, istirahat splinti ve egzersizleri ile birlikte uygulanan betametazon enjeksiyonu ile betametazon fonoforezinin eşit düzeyde KTS tedavisinde etkili olduğu bulunmuştur. Betametazon fonoforezi non-invaziv bir yöntem olması nedeniyle enjeksiyona tercih edilebilecek bir yöntemdir. Türk Fiz Tıp Rehab Derg 2011;57:119-23.

Anahtar Kelimeler: Karpal tünel sendromu, steroid enjeksiyonu, fonoforez

\section{Summary}

Objective: We aimed to compare the clinical outcomes of corticosteroid injection and phonophoresis in patients with carpal tunnel syndrome (CTS). Materials and Method: In this study, we included forty hands of 32 patients who were diagnosed with CTS on the basis of electromyography and physical evaluation and who had complaints of paresthesia and pain in the hands were included to the study. The patients were separated into two groups. Betamethasone injection, splint and exercise were applied to the first group ( 20 hands) and betamethasone phonophoresis, splint and exercise were applied to the second (20 hands) group. Pain was evaluated by the visual analog scale (VAS), severity of paresthesia by the Liken scale, symptom severity and functional capacity by the Boston Questionnaire: Symptom Severity Scale and Functional Capacity Scale, grip strength by Jamar hand dynamometer, lateral and pulp finger strength by pinchmeter, and finger dexterity by the Grooved Pegboard test.

Results: Both groups had statistically significant improvement in pain, severity of paresthesia, hand grip and finger strength, symptom severity, functional capacity and finger dexterity at the end of the 3rd month $(p<0.05)$. However, no statistically significant difference was found between the groups for any of the parameters ( $p>0.05)$.

Conclusion: At the end of the 3rd month, betamethasone injection and betamethasone phonophoresis combined with splinting and exercise treatment were equally effective in the management of CTS. Betamethasone phonophoresis can be preferable to injection therapy as it is a non-invasive method.Turk J Phys Med Rehab 2011;57:119-23.

Key Words: Carpal tunnel syndrome, corticosteroid injection, phonophoresis 


\section{Giriş}

Karpal tünel sendromu (KTS), median sinirin karpal tünelden geçerken basıya uğraması sonucu meydana gelir. Median sinir lezyonlarının en sık görülen şeklidir $(1,2,3)$. En sık görülen KTS nedeni herhangi bir etiyolojik etkenin saptanmadığı idiyopatik KTS'dir. Literatürde KTS etiyolojisi ile ilgili olarak endokrinolojik bozukluklar, romatolojik hastalıklar, amiloidoz, tümöral oluşumlar, travmatik durumlar, anatomik varyasyonlar ve enfeksiyonlar gibi etkenler sorumlu tutulmuştur $(2,3)$. KTS kliniğinde ilk belirtiler noktürnal ağı ve parestezilerdir ve bu yakınma başlangıçta subjektif tek belirti olarak karşımıza çıkar. Daha ileri dönemlerde tenar kaslarda güçsüzlük ve atrofi, az sayıda olguda Raynaud fenomeni ve diğer otonomik sempatik sinir tutuluşuna ait bulgular olabilir. Vazomotor belirtiler, büllöz ülserasyonlar görülebilir $(3,4,5)$. KTS'de tanı; anamnez, klinik semptomlar, fizik muayene bulguları ile bu bulguların elektronörofizyolojik olarak desteklenmesine dayanır $(2,3)$. KTS'nin konservatif tedavisinde uygulanan yöntemler çeşitlidir ve bu yöntemlerin birbirlerine üstünlükleri tartışmalıdır. KTS'nin konservatif tedavisi splint kullanımı, steroid enjeksiyonları, steroid olmayan non-steroidal anti-inflamatuvar ilaçlar, fizik tedavi ajanları, aktivite modifikasyonu ve iş değiştirilmesi gibi yaklaşımları içerir (6).

Bu çalışmanın amacı, KTS'li hastaların tedavisinde kortikosteroid fonoforezi, atel, egzersiz ile lokal kortikosteroid enjeksiyonu, atel, egzersiz tedavilerinin etkinliğinin klinik bulgular açısından karşılaştırılmasıdır.

$\mathrm{Bu}$ çalışmanın amacı, KTS'li hastaların tedavisinde atel ve egzersiz uygulamalarına eklenen kortikosteroid fonoforezi ve lokal kortikosteroid enjeksiyonu etkinliğinin klinik bulgular açısından karşılaştırılmasıdır.

\section{Gereç ve Yöntem}

Kliniğimize Şubat 2009 ile Temmuz 2009 arasında, ellerinde ağıı ve uyuşma yakınması ile başvuran, klinik ve elektrofizyolojik olarak hafif-orta düzeyde idiopatik KTS tanısı koyulan 32 hasta (29 kadın, 3 erkek, 40 el) çalışmaya dahil edildi. Çalışmaya alınma kriterleri;

1. Elin palmar yüzüne yayılan parestezi, ağrı veya vazomotor semptomların olması,

2. Tinel testi, Phalen testi veya karpal kompresyon testinden en az bir tanesinin pozitif olması,

3. Elektrofizyolojik olarak ılımlı hafif veya orta dereceli KTS tanısı konmuş olması (median sinir distal motor latansı 4,2 ms. üzerinde olanlar ve median sinir duysal iletim hızı $50 \mathrm{~m} / \mathrm{sn}$ 'nin altında olanlar),

4. Semptomların en az üç aydır mevcut olmasıydı.

Servikal radikülopati ya da polinöropati tanısı olanlar; KTS'ye neden olabilecek hastalıkları olanlar (diyabetes mellitus, akut travma, romatolojik hastalıklar, gebelik, hipotiroidi, hipertiroidi vb.), KTS için medikal tedavi alanlar, fizik tedavi uygulananlar, steroid enjeksiyonu ve cerrahi uygulanmış hastalar; ultrason (US) veya kortikosteroid enjeksiyonu uygulanmasına kontrendike bir medikal problemi olanlar çalışma dışı bırakıldı.

Hastalar basit randomizasyon (yazı/tura) yöntemi kullanılarak iki gruba ayrıldı. On altı hastanın 20 eline $6,43 \mathrm{mg}$ betametazon dipropiyonat, 2,63 $\mathrm{mg}$ betametazon sodyum fosfat ampul (Diprospan ampul ${ }^{\circledast}$, Schering Plough) bir kez uygulandı. Lokal steroid enjeksiyonu aseptik koşullarda, bilek dorsifleksiyonda sabitlenerek, insülin enjektörü ile palmaris longus ile fleksör karpi radialis kasları arasına palmar distal piliden $45^{\circ}$ lik açıyla girilerek uygulandı. İkinci gruptaki hastalara (20 el) iki hafta süreyle, haftada 5 gün, günde 10 dakika olmak üzere $1,0 \mathrm{~W} / \mathrm{cm}^{2}$ dozda, US karpal tünel üzerine sirküler tarzda darbeleme/vuruş (stroking) tekniği ile ve iletici ajan olarak \% 0,1 bethametasone valerate krem (Betnovate $\mathrm{krem}^{\circledast}$, GlaxoSmith Kline) sürülerek steroid fonoforez tedavisi uygulandı. Her iki grup üç ay süre ile istirahat ateli ve el, el bileği eklem hareket açıklığı (EHA) egzersizleri, izometrik egzersizler ve sinir kaydırma egzersizlerini uyguladı. Sinir kaydırma egzersizleri ev programı şeklinde gösterildi. Bilateral KTS'si olan hastaların her iki eli için değerlendirmeler ayrı ayrı yapıldı.

Tüm hastaların başlangıçta demografik özellikleri, yakınmalarının süresi, mesleği ve dominant elleri kaydedildi. Tam kan sayımı, eritrosit sedimentasyon hızı, rutin kan biyokimyası (açlık kan şekeri, ürik asit, BUN, kreatinin, karaciğer fonksiyon testleri, elektrolitler), C-reaktif protein, romatoid faktör, tiroid fonksiyon testleri istendi. Elektronörofizyolojik inceleme yapıldı.

Hastaların fizik muayenesinde atrofi ve distrofik değişikliklerin varlığı kaydedildi; Tinel, Phalen ve karpal kompresyon testleri uygulandı, motor ve duysal değerlendirme yapıldı; derin tendon refleksleri ve patolojik refleksler değerlendirildi.

Tüm hastaların başlangıçta ve tedaviden sonraki 3. ayda değerlendirilmeleri yapıldı. Gece istirahatte ve gündüz hareketle olan ağrı düzeyleri vizüel analog skala (VAS) ile değerlendirildi. Uyuşma şiddeti; 0: hiç yok, 1: hafif, 2: orta, 3: şiddetli olarak Likert skalasına göre derecelendirildi. Fonksiyonel Kapasite Skalası (FKS) ve Boston Semptom Şiddet Ölçeği (BSŞÖ) uygulandı. Hastaların el becerisi, Grooved Pegboard (Model 32025, Lafayette Instrument Company) el beceri testi ile değerlendirildi. Bu gereç 25 adet anahtar şeklinde delik içeren bir kare platformdan oluşmaktaydı. Hastalardan bu deliklere uygun 25 adet silindir şeklinde çiviyi hızı bir şekilde alıp deliklerin içine yerleştirmeleri, sonra çıkarmaları istendi. Bu sırada kronometre ile süre (sn) ölçüldü. El kavrama gücü North Coast ${ }^{\mathrm{TM}}$ Jamar el dinamometresi ile değerlendirildi. Ölçümler dirsek $90^{\circ}$ fleksiyonda, el bileği nötral pozisyonda iken yapıldı. Lateral ve parmak ucu kavrama gücü BaselineR Pinçmetre ile değerlendirildi. Her ölçüm üçer kere, 15 dakika dinlenme aralarıyla yapılıp ortalamaları alındı. Hastaların tümüne çalışmayla ilgili bilgilendirme yapıldı ve olur formu alındı. Çalışmamız için etik kurul onayı alındı.

Araştırmada elde edilen verilerin güvenilirliğinin değerlendirilmesinde (veri sayısının yeterliliği için) SPSS 16.0 (Statistical Program For Social Science) programı \%95 güvenirlilik seviyesinde, Cronbach's Alpha ve Item Total Correlations analizi yöntemleri kullanıldı. Sonuç (güvenilirlik düzeyi) \%76,93 olarak bulundu.

Windows için SPSS sürüm 16.0 programı kullanılarak hastaların demografik ve klinik özelliklerinin tanımlayıcı istatistikleri yapıldı. Grup içi karşılaştırmalar non-parametrik test kullanılarak Wilcoxon testi ile, gruplar arası karşılaştırmalar non-parametrik test kullanılarak MannWhitney $U$ testi ile, iyileşmeler arasındaki korelasyon ise Spearman korelasyon analizi ile yapıldı. $p<0,05$ değeri anlamlı kabul edildi.

\section{Bulgular}

Çalışmaya alınan 32 hastanın $29(\% 90,6)^{\prime} u$ kadın, $3(\% 9,3)^{\prime} u$ erkekti. Hastaların \%28'inde $(n=9)$ bilateral tutulum, \%68'inde 
( $n=22)$ ise dominant el tutulumu mevcuttu. Tinel testi 40 elin $\% 30$ 'unda, Phalen testi $\% 37,5$ 'inde, karpal kompresyon testi $\% 60$ 'ında pozitif bulundu. Illk değerlendirmede hastaların 5'inde tenar atrofi saptandı. Hastaların çoğu $(\% 78,1)$ ev hanımıydı. Mesleği iş̧̧i olan hastaların (\%7) tümü el aktivitesi yüksek olan işlerde çalışmaktaydı. Hasta grupları arasında yaş ortalamaları ve hastalık süreleri ve başlangıçta tüm parametrelerde istatistiksel olarak anlamlı fark yoktu ( $p>0,05)$ (Tablo 1$)$.

Tablo 1. Grupların tedavi öncesi tüm parametreler açısından karşılaştııılması.

\begin{tabular}{|c|c|c|c|}
\hline & $\begin{array}{l}\text { Fonoforez } \\
\text { Grubu }(n=20)\end{array}$ & $\begin{array}{l}\text { Enjeksiyon } \\
\text { Grubu }(n=20)\end{array}$ & $\begin{array}{c}p \\
\text { değeri }\end{array}$ \\
\hline Yaş (yıl) & $45,7 \pm 10,3$ & $41,3 \pm 11,2$ & 0,250 \\
\hline Cinsiyet (K/E) (n) & $18 / 2$ & $19 / 1$ & 0,500 \\
\hline Yakınma süresi (ay) & $53,7 \pm 83,1$ & $27,5 \pm 37,5$ & 0,430 \\
\hline VAS gece $(0-100)$ & $49 \pm 32,7$ & $51,2 \pm 25,5$ & 0,870 \\
\hline VAS gündüz (0-100) & $38,5 \pm 31,3$ & $41,5 \pm 32,6$ & 0,814 \\
\hline $\begin{array}{l}\text { Uyuşma şiddeti } \\
\text { (Likert 0-3) }\end{array}$ & $2,4 \pm 0,7$ & $2,6 \pm 0,8$ & 0,290 \\
\hline FKS & $2,36 \pm 0,67$ & $2,66 \pm 0,85$ & 0,249 \\
\hline BSŞÖ & $2,87 \pm 0,62$ & $2,84 \pm 0,89$ & 0,978 \\
\hline El kavrama gücü (kg) & $18,3 \pm 6,3$ & $19,1 \pm 6,8$ & 0,787 \\
\hline Lateral kavrama gücü $(\mathrm{kg})$ & $3,9 \pm 1,3$ & $3,6 \pm 0,9$ & 0,579 \\
\hline Parmak ucu gücü $(\mathrm{kg})$ & $3,5 \pm 1,6$ & $3,4 \pm 1,1$ & 0,839 \\
\hline Pegboard testi (sn) & $88,4 \pm 19,8$ & $88,3 \pm 20,4$ & 0,903 \\
\hline \multicolumn{4}{|c|}{$\begin{array}{l}\text { FKS: Fonksiyonel Kapasite Skalası BSŞÖ: Boston Semptom Şiddeti Ölçeği } \\
\text { VAS:Vizüel Analog Skala } \\
p<0,05 \text { istatistiksel olarak anlamlı }\end{array}$} \\
\hline
\end{tabular}

Enjeksiyon uygulanan grupta tedavi öncesi ve tedavi sonrası grubunda TÖ ile TS 3.ayda değerlendirilen tüm parametreler karşılaştıııldığında, gündüz ağrısı $(p=0,001)$, gece ağrısı $(p=0,000)$, BSŞÖ'de anlamlı oranda düzelme $(p=0,000)$; el kavrama gücü $(p=0,000)$, parmak ucu $(p=0,001)$ ve lateral kavrama güçlerinde $(p=0,030)$ istatistiksel olarak anlamlı oranda artış saptandı. İnce el becerisi gerektiren ve saniye cinsinden süre ile değerlendirilen Pegboard testinde 3. ayın sonunda istatistiksel olarak anlamlı düzeyde düzelme görüldü $(p=0,002)$. FKS'de anlamlı oranda azalma (düzelme) saptandı $(p=0,001)$ (Tablo 2 ).

Fonoforez grubunda ise 3 . ay sonunda gündüz ağrı $(p=0,012)$, gece ağrı $(p=0,001)$, FKS ve BSŞÖ'de istatistiksel olarak anlamlı düzelme saptandı $(p<0,05)$. El kavrama gücünün ve parmak ucu kavrama güçlerinin istatistiksel olarak anlamlı oranda arttığı saptandı $(p<0,05)$ (Tablo2).

Gruplar 3. ayın sonunda tüm parametrelerde gözlenen iyileşme miktarı açııından karşılaşııııldığında, her iki grup arasında istatistiksel olarak anlamlı fark saptanmadı $(p>0,05)$ (Tablo 2).

Hem fonoforez grubunda hem de enjeksiyon grubundaki hastaların uyuşma şiddeti Likert skalasına göre değerlendirildiğinde, 3.ayın sonunda başlangıca göre istatistiksel olarak anlamlı düzelme olduğu görüldü $(p=0,000, p=0,000)$. Fonoforez grubunda başlangıçta hastaların $\% 45^{\prime}$ inde, enjeksiyon grubunda ise $\% 70$ 'inde şiddetli düzeyde (Likert 3) uyuşma şikayeti varken tedavi sonrası her iki grupta da şiddetli düzeyde şikayeti olan hasta yoktu. Gruplar 3.ayda ortalama uyuşma şiddeti açısından karşılaştıııldıklarında istatistiksel olarak anlamlı fark saptanmadı $(p=0,117)$ (Tablo 3).

Fonksiyonel kapasite skalasındaki düzelme ile el kavrama gücü $(p=0,016 r=-0,380)$, parmak ucu kavrama $(p=0,003 r=-0,451)$ ve lateral kavrama güçlerindeki iyileşme $(p=0,013 \quad r=-0,388)$, Pegboard testindeki düzelme $(p=0,033, r=0,338)$ arasında orta düzeyde korelasyon; BSşÖ'deki düzelme $(p=0,000, r=0,763)$ ile ise istatistiksel olarak çok iyi düzeyde korelasyon olduğu belirlendi.

Tablo 2. Grupların tedavi öncesi ile tedavi sonrası 3.ay sonuçlarının grup içi ve gruplar arası karşılaştırılması.

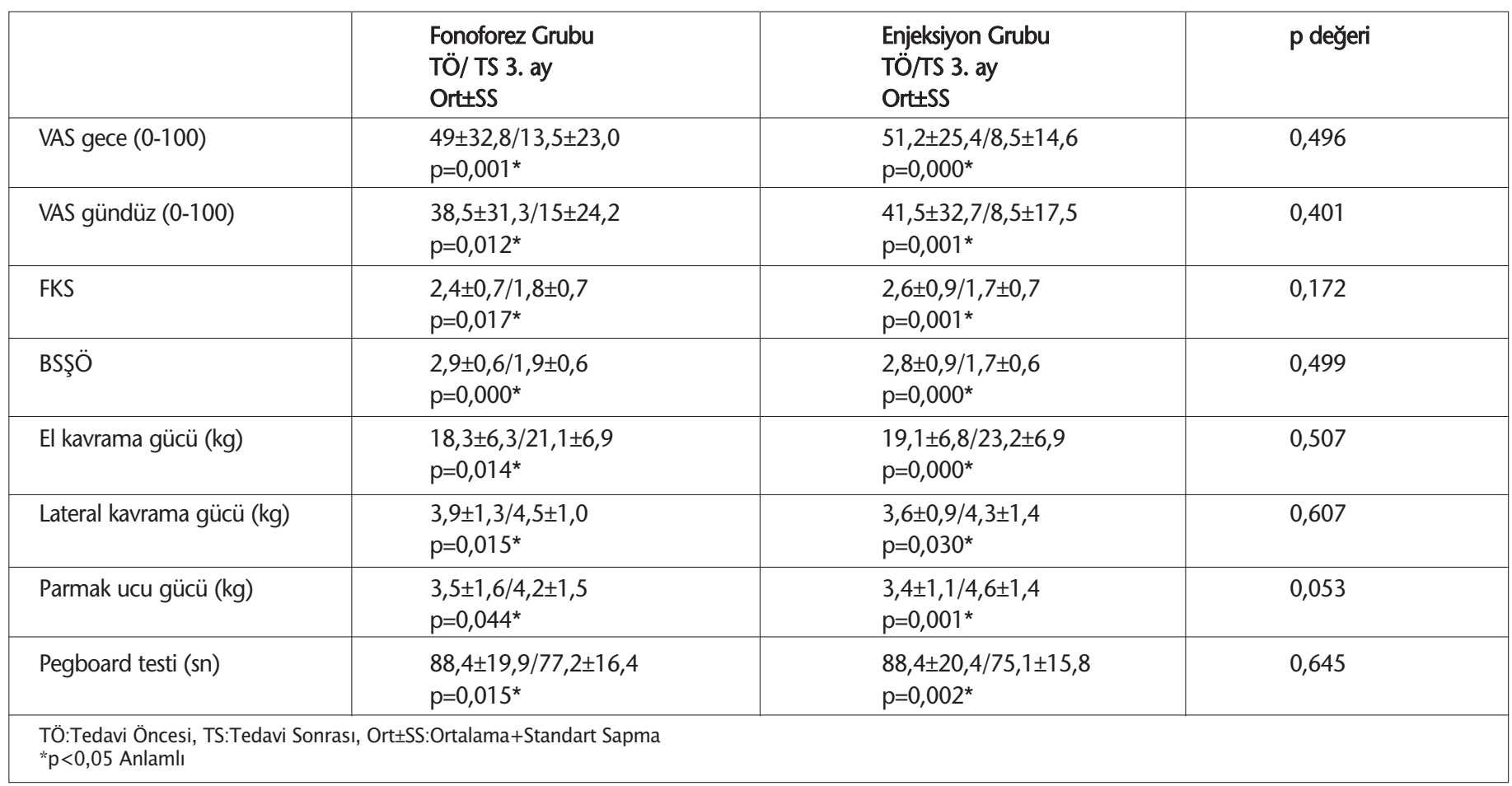


Grooved Pegboard test süresi ile el kavrama gücü, parmak ucu kavrama ve lateral kavrama gücü ve BSŞÖ'deki düzelme arasında ise anlamlı bir korelasyon saptanmadı ( $p>0,05)$ (Tablo 4).

\section{Tartışma}

Median sinirin karpal tünelde kompresyonu ile oluşan, genel popülasyonda \%10 görülen KTS, sıklıkla bilateral olabilen, geceleri daha fazla olan parestezi, ağrı, tutukluk gibi şikayetler ile birlikte kavrama gücünde azalma ve elde beceri kaybına yol açabilen bir tuzak nöropatisidir (1).

Hastalarımızda el-el bileği ağrısı, \%70'inde gündüz, \%80'inde ise gece mevcuttu. Hastaların çoğunda ise $(\% 97,5)$ ilk üç parmakta uyuşma ve parestezik şikayetler mevcuttu. Diğer çalışmalarda da uyuşma en sık gözlenen semptom olarak bildirilmektedir $(7,8)$. Literatürde ayrıca bilateral tutulum oranlarının \%22 ile \%67 arasında değiştiği $(1,4-6)$ ve sıklıkla ve ciddi olarak dominant elin etkilenmeye eğilimli olduğu bildirilmektedir (9-11). Çalışmamızda benzer şekilde hastaların \%28`inde bilateral tutulum ve \%68'inde dominant el tutulumu mevcuttu.

Hastaların \%30'unda Tinel testi, \%37,5' inde Phalen testi pozitif bulunmuştur. Değişik çalışmalarda Tinel testi pozitifliği oranları $\% 27$ ile \%80 arasında geniş bir yelpazede verilmektedir ve sensitivitesi düşük bir test olduğu bildirilmektedir $(9,12)$. Phalen testi rutin olarak kullanılan yaygın bir testtir ve \%70-80 gibi sensitivite oranları verilmiştir $(9,12)$. Yapılan çalışmalarda ise en yüksek sensitivite \%86 ile Flick işareti ve \%84 ile karpal kompresyon testlerinden elde edilmiştir. Durkan karpal kompresyon testinin \%87 sensitif, \%90 spesifik olduğunu göstermiştir $(13,14)$.

KTS'nin konservatif tedavisinde en sık kullanılanlar lokal ve sistemik steroid kullanımı, steroid olmayan anti-inflamatuvar ilaçlar, diüretikler, pridoksine, istirahat splintleri, ultrason ve laserdir (16).

Kortikosteroidlerin karpal tünel içine yapılan lokal enjeksiyonu invaziv bir girişim olmasına rağmen günümüzde kabul edilmiş bir tedavi yöntemidir. Steroid enjeksiyonu sonrası hastalık semptomlarının düzeldiği birçok çalışmada gösterilmiştir $(16,17)$. Gelberman ve ark. (1) 41 hastada yapılan prospektif bir çalışmada, tek bir steroid enjeksiyonu ile üç hafta istirahat splinti uygulamış ve hafif ve orta derecede semptomu olan KTS'lilerde başarılı sonuçlar elde etmişlerdir.

Fonoforez; kortikosteroidler, lokal anestezikler ve salisilatlar gibi farmakolojik ajanların transdermal olarak uygulandığı spesifik bir US uygulama yöntemidir. KTS'de transdermal steroid uygulamaları, enjeksiyon ile oluşabilecek yan etkilerin görülmesini engelleyebilir (18).

Tablo 3. Likert skalasına göre derecelendirilen uyuşma şiddetinin gruplar arası ve grup içi karşılaştırması.

\begin{tabular}{|l|l|l|l|}
\hline & $\begin{array}{l}\text { Fonoforez grubu } \\
\mathrm{n}=20 \\
\text { TÖ/TS n(\%) }\end{array}$ & $\begin{array}{l}\text { Enjeksiyon grubu } \\
\mathrm{n}=20 \\
\text { TÖ/TS n(\%) }\end{array}$ & p değeri \\
\hline Yok & $0 / 12(0 / 60)$ & $1 / 16(5 / 80)$ & \\
Hafif & $4 / 7(20 / 35)$ & $0 / 2(0 / 10)$ & \\
Orta & $7 / 1(35 / 5)$ & $5 / 2(25 / 10)$ & 0,117 \\
Şiddetli & $9 / 0(45 / 0)$ & $14 / 0(70 / 0)$ & \\
& $\mathrm{p}=0,000^{*}$ & $\mathrm{p}=0,000^{*}$ & \\
\hline \multicolumn{2}{|l}{ TÖ:Tedavi Öncesi, TS:Tedavi Sonrası } \\
*p<0,05 Anlamlı
\end{tabular}

Koeke ve ark. (2) sıçan tendonunda doku tamir sürecinin araştırıldığı bir çalışmada topikal hidrokortizon, US ve fonoforezi karşılaştırmış ve fonoforez tedavisinin doku tamirinde en etkili yöntem olduğunu saptamışlardır. Bu etki US'nin, doku tamir sürecini hızlandırması ile birlikte hidrokortizonun transdermal olarak tendonlarda terapötik konsantrasyona ulaşmasını sağlamasına bağlanmıştır. Plasebo kontrollü çalışmalarda KTS'de US uygulamaları ile $\left(1,0 \mathrm{~W} / \mathrm{cm}^{2}, 15 \mathrm{dk} /\right.$ seans, 5 seans/hafta) 2 . hafta, 7. hafta ve 8 . ay değerlendirmelerde plaseboya $\left(0 \mathrm{~W} / \mathrm{cm}^{2}\right)$ kıyasla, ağrı, parestezi ve hipoestezide $\left(0 \mathrm{~W} / \mathrm{cm}^{2}\right)$ anlamlı düzelme olduğu gösterilmiştir (19).

Fonoforezin steroid penetrasyonu üzerine etkisini inceleyen çelişkili yayınlar vardır. Davick ve ark. (3) $0,5 \mathrm{~W} / \mathrm{cm}^{2}, 870 \mathrm{kHz}, 8$ dakika US uygulaması ile radyoaktif işaretli \%5 veya \%10'luk kortizolün epidermis içine penetrasyonunda artış olduğunu fakat kas ve eklem içine penetre olmadığını göstermiştir.

Tuncay ve ark. (20) 36 hastayla yaptıkları bir çalışmada bir gruba üç hafta süreyle haftada $3 \mathrm{kez} 10$ dakika betametazon ile steroid fonoforezi, diğer gruba lokal betametazon enjeksiyonu uygulanmış ve tüm hastalara el bileğini nötral pozisyonda tutan istirahat splinti verilmiştir. Her iki grupta da hastaların semptomlarının düzeldiğini ve enjeksiyon tedavisinin elektronörofizyolojik bulgular üzerine de olumlu etkileri olduğunu göstermiştir. Her iki yöntemin de KTS'de etkili tedavi seçenekleri olduğu bildirilmektedir.

Karatay ve ark. (18) ise steroid enjeksiyonu, steroid fonoforezi ve steroid iyontoforezini karşılaştırdıkları çalışmada, 1. ayın sonunda gece ağrısında, Boston semptom ölçeği ve fonksiyonel statüde tüm gruplarda anlamla düzelme görülürken, gruplar arasında anlamlı fark saptanmamıştır. Klinik parametrelerdeki anlamlı düzelme 6. ayda steroid enjeksiyonu ve fonoforez grubunda devam ederken iyontoforez grubunda devam etmediği gösterilmiştir. KTS'de steroid fonoforezinin, steroid enjeksiyonuna benzer etkileri nedeniyle yararlı bir tedavi olabileceği belirtilmiştir.

Çalışmamızda benzer şekilde her iki grupta 3. ayın sonunda ağrı, parestezi, semptom şiddeti, fonksiyonel durum ve kas gücün-

Tablo 4. Kavrama güçleri, Fonksiyonel Kapasite Skalası ve Boston Semptom Şiddet Ölçeğindeki düzelmeler arasındaki korelasyon.

\begin{tabular}{|c|c|c|}
\hline$n=40$ & FKS & Pegboard testi \\
\hline El kavrama gücü & $\begin{array}{l}\mathrm{p}=0,016^{*} \\
\mathrm{r}=-0,380\end{array}$ & $\begin{array}{l}p=0,527 \\
r=-0,103\end{array}$ \\
\hline Parmakucu gücü & $\begin{array}{l}\mathrm{p}=0,003^{*} \\
\mathrm{r}=-0,451\end{array}$ & $\begin{array}{l}p=0,732 \\
r=-0,056\end{array}$ \\
\hline Lateral kavrama gücü & $\begin{array}{l}\mathrm{p}=0,013^{*} \\
\mathrm{r}=-0,388\end{array}$ & $\begin{array}{l}p=0,320 \\
r=-0,161\end{array}$ \\
\hline BSŞÖ & $\begin{array}{l}\mathrm{p}=0,000^{*} \\
\mathrm{r}=0,763\end{array}$ & $\begin{array}{l}p=0,084 \\
r=0,277\end{array}$ \\
\hline Pegboard testi (sn) & $\begin{array}{l}p=0,033^{*} \\
r=0,338\end{array}$ & $\begin{array}{l}p=0,00 \\
r=1,00\end{array}$ \\
\hline
\end{tabular}


de grup içi anlamlı iyileşme gözlenirken, gruplar arası karşılaştırmada istatistiksel olarak anlamlı fark bulunmamıştır. Steroid fonoforezinin, steroid enjeksiyonu kadar etkili bir tedavi olduğu gösterilmiştir.

Tedavi sırasında ve sonrasında her iki gruba üç ay süresince nötral pozisyonda splint uygulamasının ve el bileğine yönelik ROM, izometrik egzersizler ve sinir kaydırma egzersizlerinin de grup içi iyileşmeye katkısının olduğunu düşünmekteyiz.

Akalın ve ark. (21) KTS'li 28 hastayı, dört hafta süreyle bir gruba splint diğer gruba splintle birlikte tendon ve sinir germe egzersizleri verilmek üzere iki gruba ayırdığında; her iki grupta da klinik, hasta kaynaklı ve nörofizyolojik bulgularda istatistiksel olarak anlamlı düzelme gösterilmiştir.

Çalışmamızda hastaların fonksiyonel kapasitelerindeki düzelmenin, el kavrama gücü ve parmak ucu ve lateral kavrama güçlerinde artış ve aynı zamanda semptom şiddetindeki düzelme ile ilişkili olduğu görüldü. El ince beceri testindeki düzelme ise semptomlardaki ve kas gücündeki düzelme ile anlamlı ilişkili bulunamadı.

Levine ve ark. (22) da Boston semptom şiddeti skalası ile fonksiyonel durum skalası arasında yüksek korelasyon olduğunu, fonksiyonel durum skalası ile kavrama gücü ve pinç gücü arasında ise orta düzeyde bir korelasyon olduğunu göstermiştir.

Sonuç olarak, KTS'li hastaların tedavisinde invaziv bir yöntem olan steroid enjeksiyonu ile steroid fonoforezinin kısa dönemde birbirine üstünlüğü olmadığı sonucuna vardık, bu nedenle her iki yöntemin de KTS tedavisinde başarılı birer tedavi seçeneği olabileceği akılda tutulmalıdır. Ancak fonoforez non-invaziv bir yöntem olması nedeniyle steroid enjeksiyonuna tercih edilebilecek bir tedavi yöntemidir. Bizim çalışmamızın kısıtlılıkları ise olgu sayısının azlığı ve uzun süreli takip sonuçlarının olmamasıdır.

\section{Kaynaklar}

1. Gelberman $\mathrm{RH}$, Aronson D, Weisman MH. Carpal-tunnel syndrome. Results of a prospective trial of steroid injection and splinting. J Bone Joint Surg Am 1980;62:1181-4.

2. Koeke PU, Parizotto NA, Carrinho PM Salate AC. Comparative study of the efficacy of the topical application of hydrocortisone, therapeutic ultrasound and phonophoresis on the tissue repair process in rat tendons. Ultrasound Med Biol 2005;31:345-50.

3. Davick JP, Martin RK, Albright JP. Distribution and deposition of tritated cortisol using phonophoresis. Phys Ther 1988;68:1672-4.

4. Yamaguchi DM, Lipscomb PR, Soule EH. Carpal tunnel syndrome. Minn Med 1965:48:22-3.

5. Phalen GS. Reflections on 21 years experience with the carpal tunnel syndrome. JAMA 1970;212:1365.
6. Dündar S, Kayhan Ö, Evinç Al. Karpal tünel sendromu ve fizik tedavi ENMG kontrollü bir klinik çalışma. Fizik Ted Rehab Derg XIII 1989;3:17-8.

7. Dawson DM, Hallet M, Millender LH. Carpal tunnel syndrome. In: Dawson DM, Hallett M, Millender LH, editor. Entrapment Neuropathies. 2nd ed. Boston/Toronto: Little Brown Company 1990. p. 25-85.

8. Loong SC. The carpal tunnel syndrome: a clinical and electrophysiological study of 250 patients. Proc Aust Assoc Neurol 1977;14:51.

9. Phalen GS. The carpal tunnel syndrome: clinical evaluation of 598 hands. Clin Orthop 1972;83:29-40.

10. Bendler EM, Greenspun B, Yu J. The bilaterality of carpal tunnel syndrome. Arch Phys Med Rehabil 1977;58:362-4.

11. Phalen GS. Spontaneous compression of the median nerve at the wrist. JAMA 1951;14:1128-32.

12. Phalen GS. The carpal tunnel syndrome: 17 years experience in diagnosis and treatment of 654 hands. J Bone Joint Surg Am 1966;48:21-228

13. Phillips WE. Validation of a diagnostic sign in carpal tunnel syndrome. J Neurol Neurosurg Psychiatry 1984;47:870-2.

14. Durkan JA. A new diagnostic test for carpal tunnel syndrome. J Bone Joint Surg 1991;73A:535-8.

15. Alfonso C, Jann S, Massa R, Torreggiani A. Diagnosis, treatment and follow-up of the carpal tunnel syndrome: a review. Neurol Sci 2010;3:243-52.

16. Marshall S,Tardif G, Ashworth N. Local corticosteroid injection for carpal tunnel syndrome. Cochrane Database Syst Rev 2002;4:CD001554.

17. Girlanda P, Dattola R, Venuto C, Mangiapane R, Nicolosi C, Messina C. Local steroid treatment in idiopathic carpal tunnel syndrome:short-and long-term efficacy. J Neurol 1993;240:187-90.

18. Karatay S, Aygul R, Melikoğlu MA, Yıldırım K, Ugur M, Erdal A, et al. The comparision of phonophoresis, iontophoresis, iontophoresis and local steroid injection in carpal tunnel syndrome treatment. Joint Bone Spine 2009;76:719-21.

19. Ebenbichler GR, Resch KL, Nicolakis P, Wiesinger GF, Uhl F, Ghanem $\mathrm{AH}$, et al. Ultrasound treatment for treating the carpal tunnel syndrome: randomised "sham" controlled trial. BMJ 1998;316:730-5.

20. Tuncay R, Ünlü E, Gürçay E, Çakçı A. Karpal tünel sendromlu hastalarda fonoforez ve lokal kortikosteroid enjeksiyonunun Boston Semptom Ciddiyet ölçeği, kavrama gücü ve elektrofizyolojik bulgular üzerine etkisi. Nobel Med 2005;1:11-4.

21. Akalin E, El O, Peker O, Senocak O, Tamci S, Gülbahar S, et al. Treatment of carpal tunnel syndrome with nerve and tendon gliding exercises. Am J Phys Med Rehabil 2002;81:108-13.

22. Levine DW, Simmens BP, Koris MJ, Daltroy LH, Hohl GG, Fossel AH, et al. A self-administered questionnaire for the assessment of severity of symptoms and functional status in carpal tunnel syndrome. J Bone Joint Surg 1993;75-A:1585-92. 